\title{
Superficial Parotidectomy by Retrograde Facial Nerve Dissection
}

\author{
Gurung $\mathrm{NV}^{1 *}$, Shrestha $\mathrm{D}^{1}$, Acharya $\mathrm{A}^{1}$, Gurung $\mathrm{A}^{1}$, Shrestha $\mathrm{S}^{1}$, Poudel $\mathrm{SR}^{1}$, Chapagain $\mathrm{A}^{1}$, Regmi $\mathrm{SM}^{2}$ \\ 'Department of Surgery, Western Regional Hospital, Pokhara, Nepal \\ ${ }^{2}$ Assistant Professor, Department of Microbiology, Gandaki Medical college \& Teaching Hospital, Pokhara, Nepal
}

\section{Keywords \\ Facial nerve, Parotidectomy, Retrograde dissection. \\ Corresponding author \\ *Dr. Narendra Vikram Gurung \\ Senior consultant surgeon \\ Department of surgery, Western \\ Regional Hospital, Pokhara, Nepal \\ Email:drnvg@hotmail.co.uk}

\begin{abstract}
Introduction: Tumors of the salivary gland are relatively uncommon and represent less than two percentage of all head and neck neoplasms. Parotid gland tumor comprises $85 \%$ of the salivary gland tumors of which $80 \%$ are being benign. Superficial parotidectomy is the commonest procedure done for parotid tumors which can be performed by either anteretrograde or retrograde facial nerve dissection technique.

Methods: Outcome of 60 patients after superficial parotidectomy with retrograde facial nerve dissection has been studied.

Results: Total of 60 patients had been studied. Complications like facial nerve weakness, Freys syndrome, salivary fistula, and wound infection were taken into account. Among them, 13.33\% patients developed temporary facial nerve weakness, followed by temporary salivary fistula, $1.6 \%$. None of the patients developed any severe complication.

Conclusion: Superficial parotidectomy by retrograde facial nerve dissection is an easy technique to carry out with low complication rate and without compromising surgical outcome.
\end{abstract}

\section{INTRODUCTION}

The parotid gland is the most common site for salivary tumors, mostly arising in the superficial lobe, presenting as painless slow growing tumor of which $80-90 \%$ are benign with pleomorphic adenoma ${ }^{1}$.

Parotidectomy is a common surgical procedure for the treatment of benign and malignant lesions of the parotid gland. On account of the fact that the terminal branches of the facial nerve are closely related to the parotid gland, identification, protection, and preservation of the facial nerve are the central points for successful parotid surgery. There are two basic techniques for the identification and dissection of the facial nerve. The first technique is antegrade dissection where approach to the main facial trunk is the initial step followed by tracing to the bifurcation and peripheral branches ${ }^{2}$. In the second technique, retrograde dissection, peripheral branches are identified first and proceeding towards main trunk $\mathrm{k}^{3}$. Superficial parotidectomy is the most preferred method treating lesions of the parotid ${ }^{4,5}$.

\section{METHODS}

This study includes all patients who underwent superficial parotidectomy at Western Regional Hospital, Pokhara during August 2006 to August 2016. All together 60 patients underwent retrograde parotidectomy. Mean duration of surgery was calculated and intraoperative, postoperative complications were noted. The complications included were temporary facial nerve weakness, permanent facial nerve damage, wound infection, Frey's syndrome and salivary fistula. 


\section{RESULTS}

Among 60 patients 24 were males and 36 were females of age between seven to 73 years (Fig 1). Average duration of surgery was $90 \pm 10$ minutes. Temporary facial nerve weakness was developed in eight patients. One patient developed temporary salivary fistula. None of these patients developed other complications such as wound infection, permanent facial nerve damage and Frey's syndrome (Table 1). Histopathological study of biopsy specimens revealed 59 to be pleomorphic adenoma and one to be low grade mucoepidermoid carcinoma (Table 2).

Fig 1: Chart showing distribution of patients undergone superficial parotidectomy

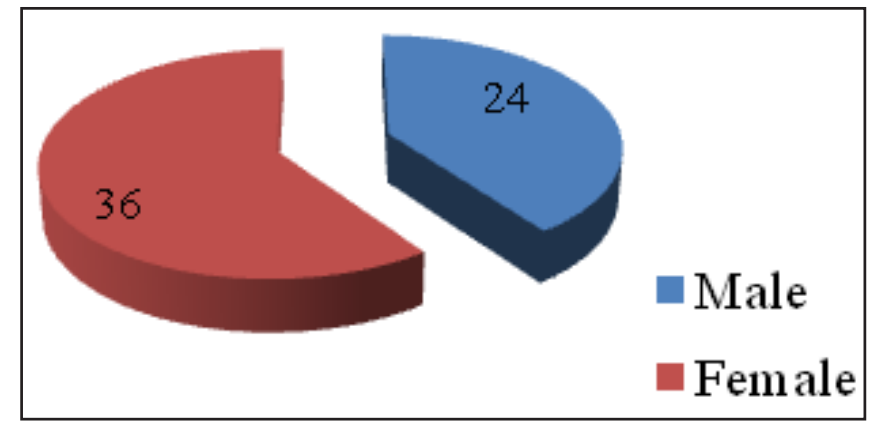

Table 1: Complication observed in the patients post surgery

\begin{tabular}{lc}
\hline \multicolumn{1}{c}{ Complications } & $\begin{array}{c}\text { Total no of } \\
\text { patients }\end{array}$ \\
\hline Temporary facial nerve weakness & $8(13.33 \%)$ \\
Permanent facial nerve damage & 0 \\
Frey's syndrome & 0 \\
Salivary fistula (temporary) & $1(1.6 \%)$ \\
Wound infection & 0 \\
\hline
\end{tabular}

Table 2: Histopathological report of biopsy specimen of the patients

\begin{tabular}{lc}
\hline Histopathological report & Total no of patients \\
\hline Pleomorphic adenoma & 59 \\
$\begin{array}{l}\text { Mucoepidermoid carcinoma } \\
\text { low grade) }\end{array}$ & 1 \\
\hline
\end{tabular}

\section{DISCUSSION}

Tumors of the salivary gland are relatively uncommon and represent less than two percent of all head and neck neoplasms. Parotid gland tumor constitutes $85 \%$ of the salivary gland tumors, $80 \%$ being benign ${ }^{1}$. Superficial parotidectomy is the preferred method treating lesions of the parotid ${ }^{4,5}$. Identification and protection of the facial nerve is central to successful parotid surgery. Two approaches antegrade ${ }^{2}$ and retrograde ${ }^{3}$ dissection are commonly used to identify and dissect the facial nerves. The antegrade approach involves identification of the facial nerve as it leaves the stylomastoid foramen. This is accomplished through identification of the nerve trunk via its relationship with the tympanomastoid suture, the targal pointer or the posterior belly of the diagastrics ${ }^{6}$. It is well known that the location of the nerve trunk may challenge even an experienced surgeon who operates on obese patients, especially those with large tumors or during revision surgery ${ }^{7}$. The retrograde approach involves identification of the peripheral branches of the facial nerve, using soft tissue landmarks. It has been observed that soft tissue landmarks of the peripheral branches are easier to identify than is commonly thought, especially with the aid of the facial nerve stimulator ${ }^{8,9}$.

This study includes all 60 patients who underwent superficial parotidectomy by retrograde facial nerve dissection at Western Regional Hospital during 10 years time period. Similar to our study Patel DK et al performed superficial parotidectomy among 214 cases with retrograde dissection of the facial nerve for clinically benign parotid tumor and found low facial nerve morbidity and optimal tumor clearance, irrespective of tumor $\operatorname{size}^{10}$. In another prospective study performed by O' Regan B et al in 138 patients with retrograde facial nerve dissection for benign parotid tumor, $66 \%$ had facial nerve weakness in first week, $38 \%$ had remained with the complication up to first month and of these $99 \%$ were fully recovered within six months ${ }^{8}$. A recent study by Scarpini $\mathrm{M}$ et al found that retrograde parotidectomy, reducing the extent of normal parotid gland removal, permit a more conservative approach than standard parotidectomy, with the same complication rates and surgical effectiveness ${ }^{11}$. Taken account, all of these studies including our study showed that retrograde facial nerve dissection technique had low complication rate.

\section{CONCLUSION}

This study shows that retrograde facial nerve dissection for superficial parotidectomy is an easy technique to carry out with minimum complications, less duration of 
surgery and without compromising surgical outcome.

\section{REFERENCES}

1. F. Charles Brunicardi, Dana K. Andersen, Timothy R. Billiar, David L. Dunn, John G. Hunter, Raphael E. Pollock. Schwartz's manual of surgery 9th ed: 2010; 507-8.

2. Snow GB. The surgical approaches to the treatment of parotid pleomorphic adenomas. In: McGurk M, Renehan A, editors. Controversies in the management of salivary gland disease. Oxford: Oxford University Press; 2001. p. 57-63.

3. Chan S, Gunn A. Conservative parotidectomy by the peripheral approach. Br J Sur. 1981;68:405-7.

4. Hobsley M. Sir Gordon-Taylor Lecture. Two themes illustrated by the surgery of the parotid salivary gland. Ann R Coll Surg Engl. 1981; 63: 264-9.

5. Wood JE, Weiland LH, Chong GC Iron GB. Pathology and surgery of primary tumors of the parotid. Surg Clin North Am. 1977; 57: 565-73.

6. Bhattacharyya N, Richardson ME. Gugino LD. An objective assessment of the advantages of retrograde parotidectomy. Otolaryngol Head Neck Surg. 2004; 131: 393-6.
7. Gunn A. Benign tumors of the parotid and submandibular gland. In: Norman JE, McGurk M, editors. Colour atlas and text of salivary glands. New York: Mosby Wolfe; 1995; p.146.

8. O' Regan B, Bharadwaj G, Bhopal S, Cook V. Facial nerve morbidity after retrograde nerve dissection in parotid surgery for benign disease: A 10-year prospective observational study. Br J oral Maxillofac Surg. 2007; 45: 101-7.

9. Wang DZ, Liu SJ. Donoff RB, Guralnick W. A modified centripetal approach to parotidectomy. J Oral Maxillofac Surg. 1985; 43: 14-9.

10. Patel DK, Ahmad Z, Mortan RP. Partial superficial parotidectomy with retrograde dissection of the facial nerve for clinically benign parotid tumors. Ann of Otology, Rhinology \& Laryngology. 2016; 125(10): 808-14.

11. Scarpini M, Amore Bonapasta S, Ruperto M, Vestri A, Bononi M, Caporale A. Retrograde parotidectomy for pleomorphic adenoma of the parotid gland: A conservative and effective approach. J Craniofac Surg. 2009 May; 20(3): 967-9. 